\title{
User Motive Factors: The Rudiments to Email Satisfactory Communication
}

\author{
CHINEDU EUGENIA ANUMUDU \\ MEGAT AL IMRAN YASIN \\ AKMAR HAYATI AHMAD GHAZALI \\ SYED AGIL ALSAGOFF \\ Universiti Putra Malaysia
}

\begin{abstract}
Our study aims to evaluate if user motive factors, comprising; cognitive needs, social integrative needs, and personal integrative needs might influence email satisfactory communication among South-East Nigerian academic staff. The study was proposed because empirical evidence has proven these user motive factors as effective elements of the uses and gratification theory; capable of influencing satisfactory communication on other virtual communication media. However, past studies appeared little or no consideration has been explicitly given towards integrating them on email interaction related-study to attest them. Therefore, this study was conducted via a quantitative research method because it required hypotheses testing to infer the outcomes and generalize them to the targeted population. Regarding the key findings of the study, it showed that South-East Nigerian academic staff email usage patterns differed from one another. However, the salient email usage pattern established that almost the majority of them mostly prefer using their email addresses to the official ones. Furthermore, the direct effects relationships demonstrated that only two dimensions of user motive construct had significant direct effects on email satisfactory communication. Whilst the social integrative needs had no significant direct effects. Nonetheless, personal integrative needs contributed most to email satisfactory communication. Conclusively, it is recommended that SouthEast Nigerian academic staff and other email users should mostly consider personal integrative needs and cognitive needs if they intend to achieve email satisfactory communication. The outcomes of our study further contributed to the virtual media satisfactory communication domain, especially the asynchronous ones.
\end{abstract}

Keywords: Email usage patterns, satisfactory communication, asynchronous virtual communications, user motive factors, South-East Nigerian academic staff.

\section{INTRODUCTION}

Insufficient data exist on whether user motive factors could influence email satisfactory communication. Therefore, this study aims to explicitly evaluate the user motive factors effects on email satisfactory communication among South-East Nigerian academic staff. Past studies that have explored email usage among Nigerian academic staff appeared little consideration has been given towards making them aware that certain motives could be obtained via email for enhancing email satisfactory communication irrespective of being a text-based medium (Bankole, 2013; Tiwari, 2016). Email is an asynchronous computermediated communication where interactions between individuals do not mostly take place in real-time. In other words, communicating entities either send or read emails at their own convenient time without the physical presence of both entities (Giesbers, Rienties, Tempelaar, \& Gijselaers, 2014). Thus, it has been identified as one of the predominant asynchronous virtual medium used for discharging tasks and disseminating corporate information in organizational settings (Swacha, 2015). 
A study has also found that email remains one of the major electronic communication internet products universally used for communication purposes despite other recent emerging communication technologies (Holz, Amann, Mehani, Wachs, \& Kaafar, 2015). This can be buttressed by the global numbers of email owners which have been estimated to be greater than 2.9 billion users towards the end of 2019, in other words, email account owners would be constituting over one- third of the world population then (Email Statistics Report, 2015-2019). The global relevance of email is not restricted to corporate firms but also a valuable communication medium used by non-corporate bodies. One of these usages is serving as an indispensable means of generating online data through interviews or survey questionnaires where face-to-face meetings seem not convenient in some cases (Bowden, \& Galindo-Gonzalez, 2015). Apart from using it as a medium of conversation, the email also serves as an avenue for collaborating and coordinating work as well as executing assignments and its management (Hanrahan, Pérez-Quiñones, \& Martin, 2016). Turnage and Goodboy (2016) further stated that email is a medium used by workers for conveying vital and beneficial feedbacks to co-workers and employers, especially those that do not cherish engaging in face-to-face communications. The scholars' findings further established that email is a medium use for resolving differences among employees.

Among academic staff as the subjects of this study, email is also one of the internet services highly valued and used by them for discharging their duties. Therefore, research has found it to be one of virtual communications universally used for facilitating interactions among lecturers and for exchange of views with students (Baeten, 2016). Moreover, it has been identified as one of the major media used by universities' administrators for liaising between lecturers and governments on scholarships, and research related-issues (Haddouch, 2017). Additionally, Manca and Ranieri (2016) established that lecturers use email to enhance and exchange professional links among themselves. In Nigeria, irrespective of the numerous challenges facing academic staff in using information and communication technologies as outlined by Omeluzor, Akibu, and Akinwoye (2016), few studies have shown that email remains the leading internet services cherished by Nigerian academic staff (Tiwari, 2016; Olatokun, 2017).

However, the prevalent concern was that email has also been criticized by Nigerian academic staff to be among virtual communication media that lacked the capacity of organizing and motivating one another. Consequently, it has been said to affect their productivities due to dissatisfactory communications (Mukoroi, 2013). This could be because they do not explicitly use email for certain motives that might motivate and gratify their desires within institutional settings. Therefore, towards devising means to enhance email satisfactory communication, user motive construct from the uses gratification theory (UGT) was employed in the study since past studies on other communication media have hypothesized it as an effective element for influencing satisfactory communications (Katz, Haas \& Gurevitch, 1974). Hence, this study aims to evaluate the direct effects of user motive factors on email satisfactory communication among South-East Nigerian academic staff. Additionally, the study aims to identify their usage patterns and the user motive factor that contributes most to email satisfactory communication. Consequently, our study is guided by the following research objectives: 
1. To identify the South-East Nigerian academic staff email usage patterns.

2. To evaluate if there are direct effects of user motive factors comprising (cognitive needs, social integrative needs and personal integrative needs) on email satisfactory communication among the South-East Nigerian academic staff.

3. To identify the user motive factor that contributes most to their email satisfactory communication.

\section{LITERATURE REVIEW}

\section{Email Usage Patterns}

Cecchinato, Cox and Bird (2015) defined email usage patterns as the time of usage, where and how university employees manage both personal and work related-email matters. The scholars further categorized using email micro-boundary as a specific pattern for managing personal and work-related issues. Congruently, Page (2015) also presented that virtual media such as email could be individually used in such a way that would allow balancing work-life burdens and realizing other personal needs.

However, Mohamed, Ku-Mahamud, Ramli and Abdullah (2017) found from a study conducted among staff in University Utara Malaysia that $46 \%$ of the respondents were using email once a day, whilst $1.5 \%$ was using it once in $2-3$ days and only $0.4 \%$ was found to weekly use it. Contrarily. Mahomed and Shah (2015) associated email usage patterns with the duration of usage. Therefore, the scholars established that greater numbers of academic staff have been using email for more than a decade. The scholars further stated that $85.8 \%$ of academic staff have a personal email address for resolving personal issues while $65.2 \%$ confirmed having work-related email for receiving job matters. Cardon and Marshall (2015) further demonstrated that email is used as the commonest means of communication for conveying teamwork interactions across corporate firms. Consequently, the scholars illustrated that $85 \%$ of professional workers intermittently interact via it on an hourly basis.

\section{Communication Satisfaction}

Communication satisfaction enables organizations to realize their progress and also assists in developing both employees and public attitudes by keeping them better informed on the events of the organizations (Alam, 2016). However, certain factors could determine organizational effective communications. This could be the availabilities of active internal conversations and integrations among employees. Nevertheless, internal integration and exterior integration were identified as the antecedents of these factors (Jacobs, Yu \& Chavez, 2016).

However, Horzum (2015) diversified the concept of communication satisfaction from virtual interaction perspectives and came up with social presence and frequency of conversations as other factors influencing it on computer-mediated forums. Similarly, Anumudu et al. (2020) demonstrated that prompt feedback, approachability, and similar personality were essential predictors to institutional satisfactory communication, especially when it has to do with text-based media productivities. Nonetheless, the study identified a similar personality as the most factor influencing satisfactory communication. Conversely, Ogara, Koh and Prybutok (2014) presented social presence and other factors comprising social influence, user experience, and perceived media richness as determinants of satisfactory communication. Agnihotri et al. (2016) further established from a virtual business-to-business scenario that information, interaction behaviour, and individual responsiveness were factors 
influencing effective communication. A recent study that investigated the factors influencing satisfactory communication in email communication within universities' settings, illustrated that uninterrupted internet facility; and low-cost subscription, homophilous manners of interactions and content technical strategies were indispensable to virtual text-based satisfactory communications (Anumudu et al., 2020).

\section{User Motive Factors and Communication Satisfaction}

The user motive is a construct from the uses and gratification theory. It is rooted in understanding the reason behind users of media choosing a particular media over another for satisfying specific needs (Katz, 1959). The user motive element was evaluated from 3 dimensions in this study. These comprised (Cognitive needs, Social integrative needs, and Personal integrative needs). Hence, previous scholars' direct effects on hypotheses outcomes between these factors and communication satisfaction on virtual communication media would be subsequently discussed.

About user motives as predictors to media satisfactory communications, Zolkepli and Kamarulzaman (2015) hypothesized the direct effects of personal and social integrative needs on social media satisfactory communications. Thus, the outcomes stated that social media provide users with the opportunity to fulfil both their communal motives and individual needs. Moreover, the direct effects relationships were found to be significant ones. Similarly, Sun et al. (2017) demonstrated significant direct effects of cognitive needs, personal integrative needs, and social integrative needs on the link-sharing tools users' satisfaction. However, social integrative needs were found to be the strongest factors that motivated users' continuance usage. Khan (2017) further established the direct effects of both socially motivating needs and cognitive needs on the gratifications of using the YouTube site. Nonetheless, social motives were identified as the most important needs. Nevertheless, engagements with contents and interactions were the antecedents that strengthened the relationships.

However, a comparative experimental study that involved conversations with face-toface and instant messaging virtual medium and also instant messaging virtual medium without face-to-face, established the direct effect of social needs on satisfaction among the communicating entities. Nevertheless, greater satisfaction was observed in the group that combined face-to-face and instant messaging virtual forums (Sacco \& Ismail, 2014). Similarly, Zhan et al. (2016) and Ang et al. (2015) found significant and positive effects of social integrative needs on satisfactory interactions via computer-mediated social media. Oh, Ozkaya and Larose (2014) also hypothesized that social support needs had a direct and positive effect on satisfactory communication via online social networking usage. Moreover, the scholars illustrated that all the social support dimensions examined in the study were strong predictors of achieving satisfactory life in online social networking sites.

Pendry and Salvatore (2015) further argued that online discussion has social benefits towards achieving satisfactory participation for the users. Thus, the scholars found that the higher the social benefits the users of online discussion obtain, the more they engage on such a site for satisfactory expectations. Congruently, the findings of Chang, Liu and Chen (2014) buttressed that integration of cognitive and social influences yielded large variance on the continuance intention of using virtual media, which eventually led to satisfactory online game usage. 
Cognitive needs have been equally found to have the most direct effects on satisfying motives behind using yahoo and Wiki for asking questions, especially in a scenario that demands interactions with unknown communicating entities. This is because cognitive needs could propel them into inquiring about unfamiliar information or seeking other people's views on relevant issues (Choi \& Shah, 2016). Contrarily, Ha et al. (2015) established insignificant direct effects of cognitive needs on the gratifications of mobile instant messengers and Facebook sites among Korean users. Whilst a good number of scholars found it as a major factor influencing satisfaction and social media continuous usage. This could be influenced by the studies' contextual and cultural differences. Therefore, in line with the previous studies' findings, the researchers hypothesized the following:

H1a: Cognitive needs have direct effects on email satisfactory communication $\mathrm{H} 1 \mathrm{~b}$ : Social integrative needs have direct effects on email satisfactory communication $\mathrm{H} 1 \mathrm{c}$ : Personal integrative needs have direct effects on email satisfactory communication

\section{Theoretical Framework}

This study was guided by the Uses and Gratification Theory (UGT) propounded by (Katz, 1959). It is a theory that focused on understanding why people prefer a particular media over others for attaining specific needs and gratifications. Thus, the theory proposes that media users actively choose a medium that can satisfy their desires irrespective of being synchronous or asynchronous communication media (Katz, Blumler \& Gurevitch, 1973). Previous scholars who have applied this theory in media usage related-studies have established that different factors were influencing the media users' choices. Consequently, a series of factors were found to be determinants of the types of communication channels people prefer to use at a particular time for gratifying their motives. Therefore, Dunne, Lawlor, and Rowley (2010) proposed that media users choose a particular social networking site over another for gratifying personal needs such as presenting and managing their identities as well as safeguarding their impersonal nature within virtual settings. Whiting and Williams (2013) further presented social communications, information search, the passing of time, entertainment, relaxation, conveniences, opinion expressions, dissemination of information, and acquiring knowledge about other people as reasons instigating them to use certain communication media. However, Ifinedo (2016) demonstrated that the rationales behind the adoption of certain social network sites are for gratifying social internalization, identifications, self-discoveries, entertainments, social enhancement, interpersonal connectivity, and individualism-collectivity. Congruently, Kang (2014) found easiness of media use as the primary factor influencing intentions of using communication technologies, followed by human connections, obtaining social utilities, task performance, and social influence motives.

Other groups of researchers identified motives like surveillance, documentation, coolness, and creativity as the reasons propelling people to utilize one media over another (Sheldon \& Bryant, 2016). While Sumter, Vandenbosch and Ligtenberg (2017) came up with motives such as love, ease of communication and excitement as other factors inducing usage of communication media. Florenthal (2015) further found that people preferred using certain media for interpersonal communications, online identifications; information, and career development motives. 
A recent comparative study conducted by Phua and Kim (2017) established that people choose to use certain communication media for bridging and bonding of social capital, media intensity, trust, tie strength, homophily, privacy concerns, and introversion. On the other hand, Luo and Remus (2014) presented that behavioural usage, satisfaction, and other antecedents such as behavioural intention and entertainment needs, as determinants of the choice of media usage. Similarly, the perceived need for satisfaction, time-waster, freedom fighter, compensator, value seeker, and ludophile were found as reasons behind preferring one media to another (De Schutter \& Malliet, 2014). Kang and Jung (2014) further identified physiological safety, belongingness, self-esteem, self-actualization, and life satisfaction as factors influencing the usage of certain smartphones over others. Nevertheless, selfactualization and continuous usage were established as antecedent factors.

Consequently, based on the predominant media users' satisfactory communication determinants as the related-studies established, the current study's conceptual framework was developed and was limited to cognitive, social integrative, and personal integrative needs towards predicting their influences on email satisfactory communication among the SouthEast Nigerian academic staff.

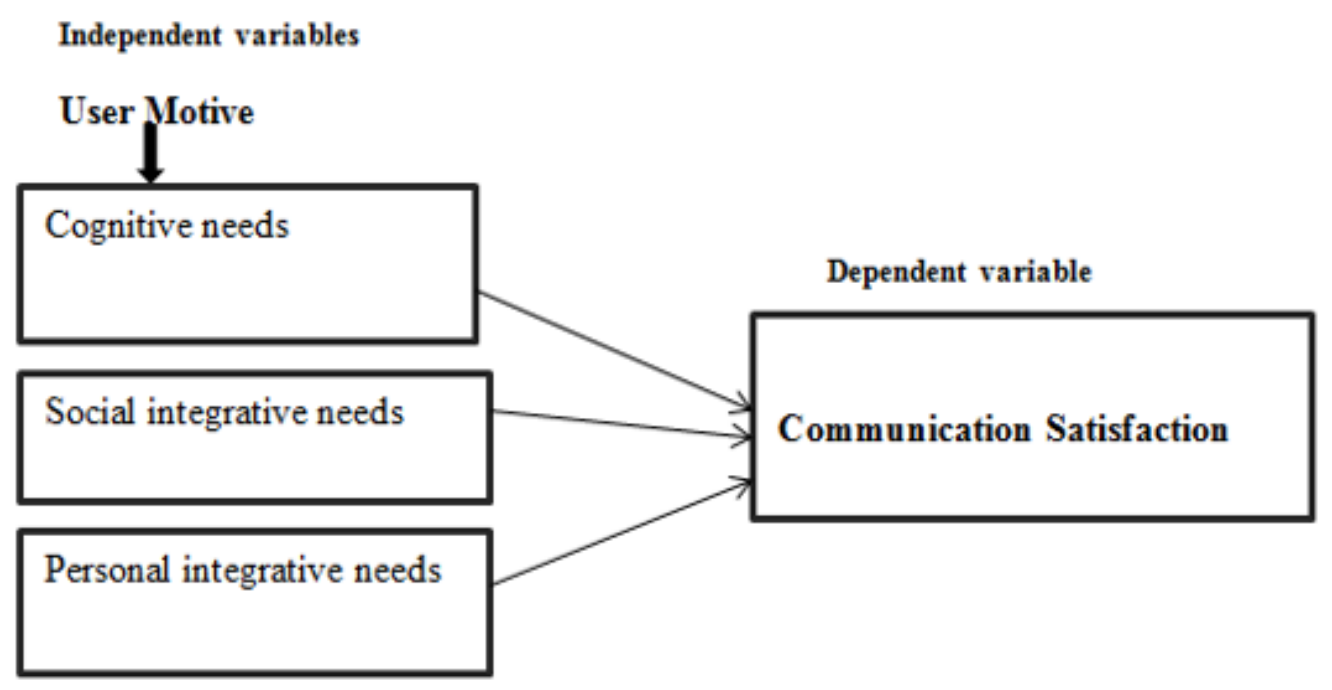

Figure 1: Conceptual Framework

\section{METHODOLOGY}

This section discussed the research design, location, and population of the study, sampling size and technique, Actual sample size used for the study, measurement, and operationalization of the variables, reliability of the instrument, and data analysis.

\section{Research Design}

Since this study's purpose was to evaluate if user motive factors have direct effects on email satisfactory communication, quantitative method research was employed. The study further measured cause and effects relationships through evaluating the concepts of the uses and gratification theory, therefore, a quantitative study was deemed the most suitable for it (Berger, 2018). The survey questionnaire was also used and collected data because it was considered appropriate for collecting data based on the respondents' opinions, be behaviours characteristics of a given population (Coppock \& McClellan, 2019). 
Location and Population of the Study

South-East Nigeria was the location of the study. The location is made of 5 states comprising: Abia, Anambra, Ebonyi, Enugu, and Imo; and the Public universities within these states were the study unit areas. Therefore, one public university was at least randomly selected from each of the 5 states. This was because each state has 2 public universities consisting of federal and state universities. Thus, 3 state and 3 federal universities were randomly chosen for the study and that made it a total of 6 selected public universities employed in the study area. In terms of the targeted population of the study, it comprised 7,160 numbers of academic staff within these 6 public universities.

\section{Sample Size and Sampling Technique}

Krejcie and Morgan's Table was the method used and determined the sample size of the study from the targeted population of 7,160 as Kitenga, Kilika and Muchemi, (2020) study outlined. The method was applied because it gave everyone in the targeted population the opportunity of being chosen. Therefore, a sample size of 364 was determined by the targeted population. Nevertheless, the sample size was subsequently increased by $23 \%$, which was additional 83 numbers of respondents. Consequently, a total of 447 questionnaires were finally shared. This was done for increasing the opportunities for obtaining better significant levels' results and confidence since more sample sizes tend to offer better findings (Funder et al., 2019). In terms of the sampling technique, probability and multistage sampling were used in administering the questionnaires because the study made use of clusters and simple random sampling techniques (Creswell, 2017).

\section{Actual Sample Size Used for the Study}

Since multistage probability sampling was used to administer the questionnaires, it initially underwent into clusters by faculties and departments before the questionnaires were finally proportionately shared among the selected departments because some of the departments had more numbers of academic staff than others. Conclusively, 363 respondents who filled the questionnaires were the actual sample size used for the study. 


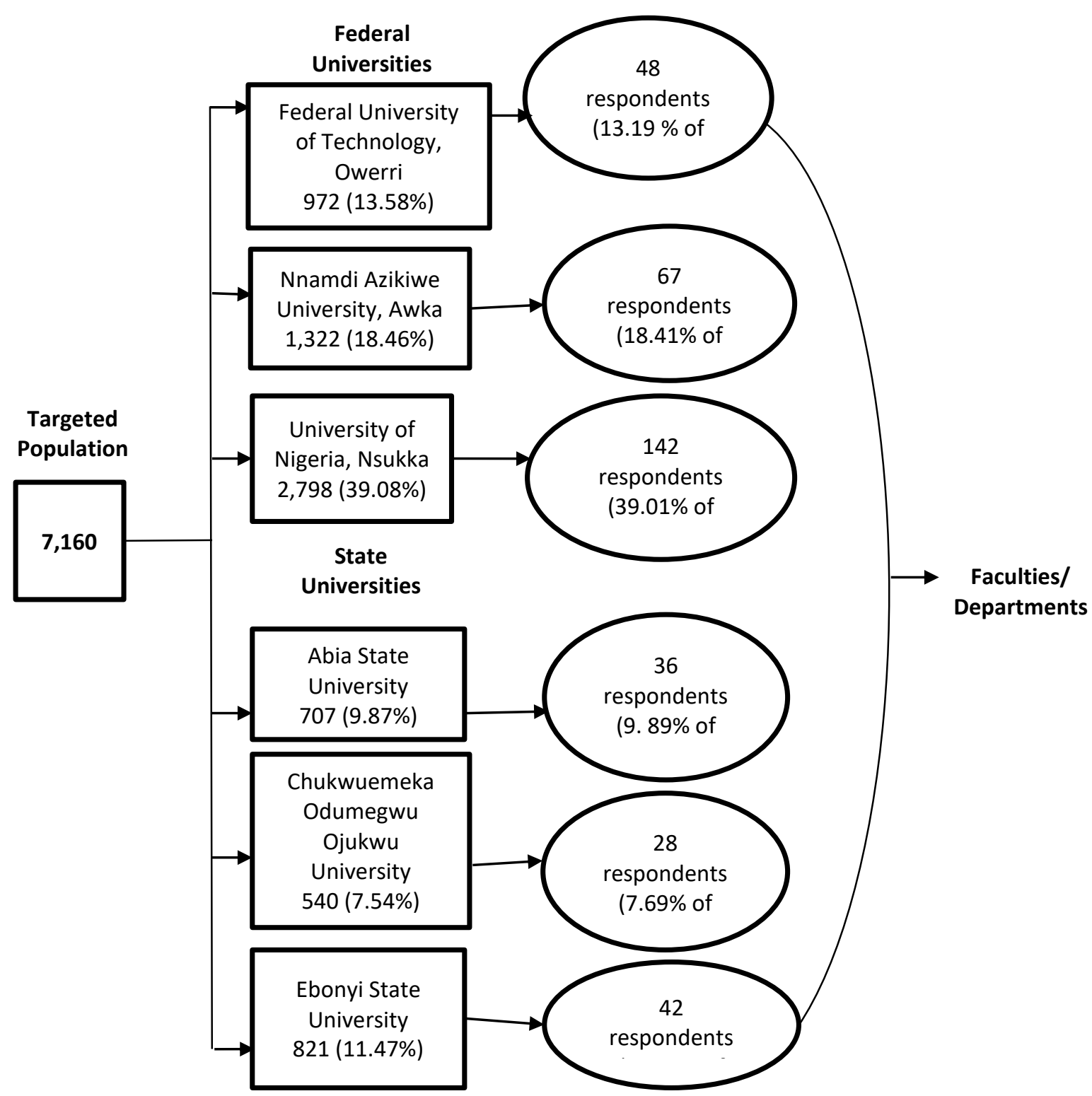

Figure 2: Actual sample size used for the study

\section{Measurement of the Variables and Operationalization of Variables}

Two types of questions were employed while designing the study's instrument. The two were closed and open-ended questions. The closed-ended ones were on a Likert scale and multiplechoice options. Whilst, the opened ended ones allowed the respondents to fill in their own opinions. Regarding the number of questions used for the study, 38 questions were used. Nevertheless, they were grouped into 4 major sections. Section $A$, was the demographic factors, Section B, was the user motive factors' items, Section C, was the communication satisfaction items and Section D was on the email usage patterns. Furthermore, Section B and $C$ were measured on a Likert scale that ranged from the following order: Strongly Disagree (1) Disagree (2) Somewhat Agree, (3) Agree, (4) strongly Agree (5).

However, communication satisfaction was the dependent variable of the study. It was contextually defined as the users' attitudinal assessment of issues, surrounding responses they receive via email as a medium of conversation. 8 questions were used to measure it. 4 
items out of the 8 were adapted from the communication satisfaction inventory developed by Down and Hazen (1977) while an item was adapted from (Pritchett et al., 2014). Two items were adopted from Iriani (2006) and add one item was self-developed.

The user motive construct was the independent variable of the study. It was contextually defined as various needs emails could be used to achieve. It was also evaluated from 3 dimensions. These comprise: (Cognitive, Social integrative, and Personal integrative needs). Cognitive needs as one of the dimensions of user motive construct entailed using email to get information for fulfilling mental and intellectual needs while social integrative needs involved using email for gratifying relationship sustenance and communal related purposes. And personal integrative needs referred to using email for resolving personal matters that are private oriented. The user motive concept was measured through the 3 dimensions with 16 items. 5 out of the 16 items were adapted from Johnson and Yang (2009) while 4 items were adapted from Page (2015). The other 3 items were adapted from Park, Kee and Valenzuela (2009) whilst the remaining 4 items were self-developed. Email usage patterns were finally examined with 9 items. 4 out of the 9 items were adopted from Mahomed (2015) while the remaining 5 items were self-developed.

\section{Pilot test/Reliability of the instrument}

Initially, a pilot study was conducted among 36 respondents to ascertain the questions' clarity and the internal consistency of the data used to measure the four variables of the study. The outcomes of the Cronbach alpha value which ranged from .839 and .869 proved that the factors were reliable. Actual study reliability was further confirmed after the data collection from 363 respondents and the Cronbach alpha values as presented in Table 1, also showed that the four variables consisting cognitive needs, social integrative needs, personal integrative needs, and communication satisfaction were all reliable because the alpha values were all $\geq .70$ as Mohamad et al. (2015) stated.

Table1: Variables' Reliability Outcomes for Pilot and Actual study

\begin{tabular}{llccc}
\hline S/N & \multicolumn{1}{c}{ Variables } & $\begin{array}{c}\text { Item } \\
\text { Numbers }\end{array}$ & $\begin{array}{c}\text { Cronbach } \\
\text { Alpha for Pilot } \\
\text { Study } \\
\text { (n=36) }\end{array}$ & $\begin{array}{c}\text { Cronbach Alpha for } \\
\text { Actual Study(n=363) }\end{array}$ \\
\hline 1 & Cognitive needs & 5 & .869 & .862 \\
2 & Social integrative needs & 5 & .864 & .851 \\
3 & Personal integrative needs & 6 & .866 & .795 \\
4 & Communication Satisfaction & 8 & .839 & .844 \\
\hline
\end{tabular}

\section{Data Analysis}

The research made use of 3 types of data analyses. These were descriptive statistics analysis, exploratory factor analysis (EFA), and Structural Equation Modeling (SEM-AMOS) analysis.

\section{a. Descriptive Statistics Analysis}

The first objective of the study on email usage patterns and the respondents' profile was described by using measures of central tendency descriptive statistics through the outcomes of Statistical Package for Social Sciences (SPSS) version 23 software. 


\section{b. Exploratory Factor Analysis (EFA)}

This was also run via SPSS to verify the dimensions' patterns since most of the items were adapted and adopted from various scholars that have previously conducted similar studies. However, the exploratory factor analysis results presented that all the eigenvalues for the individual factors' were not less than 1 according to Kaiser (1960). The entire variance percentage explained by the four factors was also not less than $60 \%$ as established by (Hair et al., 2006). Initially, 24 items were used and run the EFA, 19 items finally met the criteria. Furthermore, the Kaiser-Meyer-Olkin (KMO) for ascertaining sample size adequacy Barlett's test of sphericity established that the value .887 was greater than (.70) and Chi-square value for Barlett's test of sphericity was 3029.358 ( $d f=171, p<0.05$ ). The 4 factors comprising cognitive needs, social integrative needs, personal integrative needs, and communication satisfaction collectively explained $60.95 \%$ of the variance.

Table 2: Exploratory Factor Analysis Table

\begin{tabular}{|c|c|c|c|}
\hline Factors/Variables & Variance\% & $\begin{array}{l}\text { Eigen } \\
\text { Values\% }\end{array}$ & $\begin{array}{l}\text { Items } \\
\text { factor } \\
\text { loading }\end{array}$ \\
\hline \multicolumn{4}{|l|}{ USER MOTIVE FACTORS } \\
\hline Cognitive Needs & 8.35 & 1.587 & \\
\hline $\begin{array}{l}\text { SEB1: To get informed about the institution's academic related- } \\
\text { services via email }\end{array}$ & & & .82 \\
\hline SEB2: To get informed about campus event via email & & & .85 \\
\hline SEB3: To get informed about official issues via email & & & .81 \\
\hline $\begin{array}{l}\text { SEB4: To disseminate useful intellectual issues to co-workers } \\
\text { through email }\end{array}$ & & & .62 \\
\hline Social integrative Needs & 35.12 & 6.673 & \\
\hline $\begin{array}{l}\text { SEB6: To socially communicate with many people at the same time } \\
\text { through email }\end{array}$ & & & .75 \\
\hline SEB7: To keep in touch with alumni members through email & & & .68 \\
\hline $\begin{array}{l}\text { SEB8: To foster a mutual relationship with old friends I know via } \\
\text { email }\end{array}$ & & & .81 \\
\hline SEB9: To communicate with distanced friends via email & & & .80 \\
\hline SEB10: To keep in touch with a current friend via email & & & .75 \\
\hline Personal integrative Needs & 5.729 & 1.089 & \\
\hline SEB12: To update career related-issues issues through email & & & .61 \\
\hline SEB13: To feel connected with co-workers via email & & & .65 \\
\hline $\begin{array}{l}\text { SEB14: To enhance personal professional development through } \\
\text { email }\end{array}$ & & & .67 \\
\hline $\begin{array}{l}\text { SEB15: To store and organize personal files and attachments via } \\
\text { email }\end{array}$ & & & .72 \\
\hline Communication Satisfaction & 11.75 & 2.23 & \\
\hline SEC2: I am satisfied with accomplishing anything via email & & & .64 \\
\hline SEC3: I feel I effectively communicate through email & & & .66 \\
\hline $\begin{array}{l}\text { SEC4: I feel dissemination of information via email helps in } \\
\text { understanding others' point of views }\end{array}$ & & & .62 \\
\hline $\begin{array}{l}\text { SEC6: I feel communication via email motivates and stimulates zeal } \\
\text { for meeting the institution's targeted goals }\end{array}$ & & & .70 \\
\hline $\begin{array}{l}\text { SEC7: I feel communicating through email helps me in identifying } \\
\text { with my institution }\end{array}$ & & & .75 \\
\hline $\begin{array}{l}\text { SEC8: I feel written directives and reports through email are clear } \\
\text { and concise }\end{array}$ & & & .72 \\
\hline
\end{tabular}




\section{c. Structural Equation Modeling (SEM) Analysis}

Objective 2 and 3 were analyzed through Structural Equation Modeling (SEM-AMOS) version. SEM-AMOS is a multivariate covariance statistical software use for conducting confirmatory factor analysis (CFA), path, and multiple regressions. Moreover, it is a statistical technique use to assess dependency relationships between endogenous and exogenous variables (Hair et al., 2010). Thus, SEM-AMOS was employed in the study because it met up with normality assumptions. The normality test was established through skewness and kurtosis values, which ranged between -.392 and 1.175. Furthermore, the sample size of 363 is fit for using SEMAMOS because it was more than 200 sample sizes as Hair et al. (2010) stated. Moreover, before employing SEM-AMOS, certain criteria need to be satisfied, these are:

\section{Confirmatory Factor Analysis (CFA)}

This was conducted for the endogenous and exogenous variables of this study. The goal of CFA is to reduce many inter-correlated items for the aim of representing a lesser number of constructs (Khairani \& Makara, 2020). In this study, CFA for user motive construct which comprised the following 3 dimensions: cognitive needs, social integrative needs, and personal integrative needs were run through first-order-CFA. While, simple CFA was conducted for communication satisfaction, which was the endogenous variable. Firstly, 19 items were taken to the CFA stage, 14 items eventually scaled through. The result of the CFA demonstrated that each of the 14 items' factor loading was $\geq .5$.

\section{Construct Validity}

In this study, two kinds of validities were assessed according to Hair et al. (2010), they were: i. Convergent validity: This is also known as Average Variance Extracted (AVE). The aim of it is to ascertain that all the items jointly measured what they ought to measure. Thus, the outcome implied that all the 4 factors consisting of cognitive needs, social integrative needs, personal integrative needs, and communication satisfaction AVE were individually $\geq .5$.

\section{Discriminant Validity}

This was also met because the outcomes proved that each factor was free from multicollinearity issues. In other words, every paired factors' AVE was bigger than each factors' squared correlation matrix.

\section{Composite/Construct Reliability}

This is similar to Cronbach's alpha in SPSS; it was used to determine the internal consistency in the data used for the study. Its cut-off value in SEM-AMOS is also $\geq .70$. The 4 constructs' reliability ranged between .75 and 85 , In other words, they were all reliable.

\section{Test for Model Fit}

Model fit in SEM-AMOS is determined through the goodness of fit indices. The outcomes in the study implied that it respectively met up with at least one fit index from the 3 categories of the goodness of fit indices, which are Absolute fit, Incremental fit, and Parsimonious fit. In other words, it satisfied $<5$ cut -off for CMIN/DF, the minimum discrepancy. It also met up with $\geq .90$ cut-off for the Tucker-Lewis index (TLI) and the Root Mean Square Error of Approximation (RMSEA) was also $\leq .08$ as stipulated by (Hair et al., 2010). 
Table 3: Summary of Individual Confirmatory Factor Loadings, Construct Reliabilities and Convergent Validities Outcomes from SEM-AMOS Measurement Model Analysis

\begin{tabular}{|c|c|c|c|c|}
\hline $\begin{array}{l}\text { Items Nos } \\
\text { Section }\end{array}$ & Construct Name & $\begin{array}{l}\text { Factor Loading } \\
\geq .5\end{array}$ & $\begin{array}{l}\text { Construct Reliability } \\
(\mathrm{CR}) \geq .70\end{array}$ & $\begin{array}{l}\text { Average Variance } \\
\text { Extracted }(\geq .5)\end{array}$ \\
\hline & Cognitive Needs & & .79 & .55 \\
\hline SEB1 & & .80 & & \\
\hline SEB3 & & .76 & & \\
\hline \multirow{2}{*}{ SEB4 } & & .67 & & \\
\hline & Social Integrative Needs & & .85 & .60 \\
\hline SEB7 & & .59 & & \\
\hline SEB8 & & .88 & & \\
\hline SEB9 & & .83 & & \\
\hline \multirow[t]{2}{*}{ SEB10 } & & .76 & & \\
\hline & $\begin{array}{c}\text { Personal Integrative } \\
\text { Needs }\end{array}$ & & .75 & .52 \\
\hline SE12 & & .82 & & \\
\hline SEB13 & & .74 & & \\
\hline \multirow[t]{2}{*}{ SEB14 } & & .58 & & \\
\hline & $\begin{array}{l}\text { Communication } \\
\text { Satisfaction }\end{array}$ & & .81 & .52 \\
\hline SEC3 & & .58 & & \\
\hline SEC6 & & .72 & & \\
\hline SEC7 & & .86 & & \\
\hline SEC8 & & .69 & & \\
\hline
\end{tabular}

\section{Measurement Model}

This is the 2nd stage of SEM-AMOS analysis: Figure 3 demonstrated that the goodness of fit indices for the 4 factors was satisfied. Consequently, one out of the 3 categories of the goodness of fit indices comprising absolute fit, incremental fit, and parsimonious fit Indices was achieved as could be seen in figure.3. Invariably, minimum discrepancy (CMIN/DF) was $<5$, while, Tucker-Lewis index (TLI) was $\geq$. 90 and the Root Mean Square Error of Approximation (RMSEA) was $\leq .08$ as Hair et al. (2010) established. 


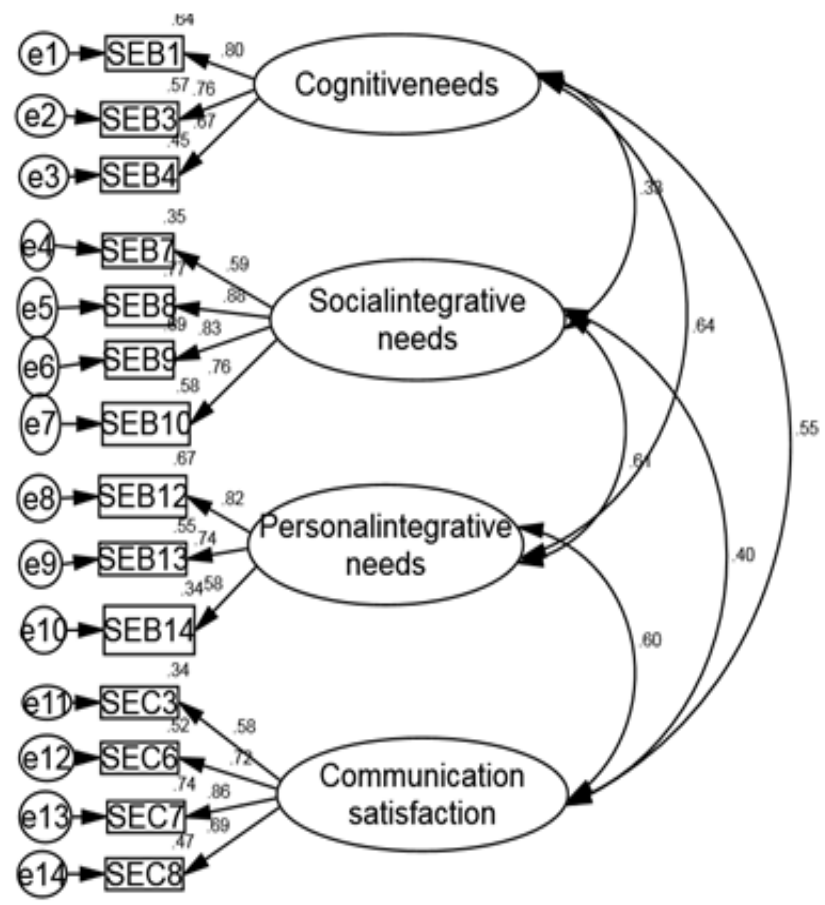

$$
\begin{aligned}
& \text { Chi-square }=143.532 \\
& \mathrm{P}(>05)=000 \\
& \text { CMINDF }(>2 / 3 / 5)=2.022 \\
& \text { CFI }(2.90)=.966 \\
& \text { IFI }(2.90)=.966 \\
& \begin{aligned}
N F I & (2,90)=935 \\
\text { TU } & (200)=056
\end{aligned} \\
& \text { TUL }(2.90)=.956 \\
& \mathrm{GFI}(\mathrm{2} .95)=.947 \\
& \text { SRMR (S08) } \\
& \operatorname{RMSEA}(S .08)=.053
\end{aligned}
$$

Figure 3: SEM-AMOS Measurement Model

\section{Structural Model}

The structural model is the last stage of SEM-AMOS. At this stage, causal effects relationships between exogenous and endogenous variables were established. Conversely, multiple regression analysis of theoretical concepts was also determined here.

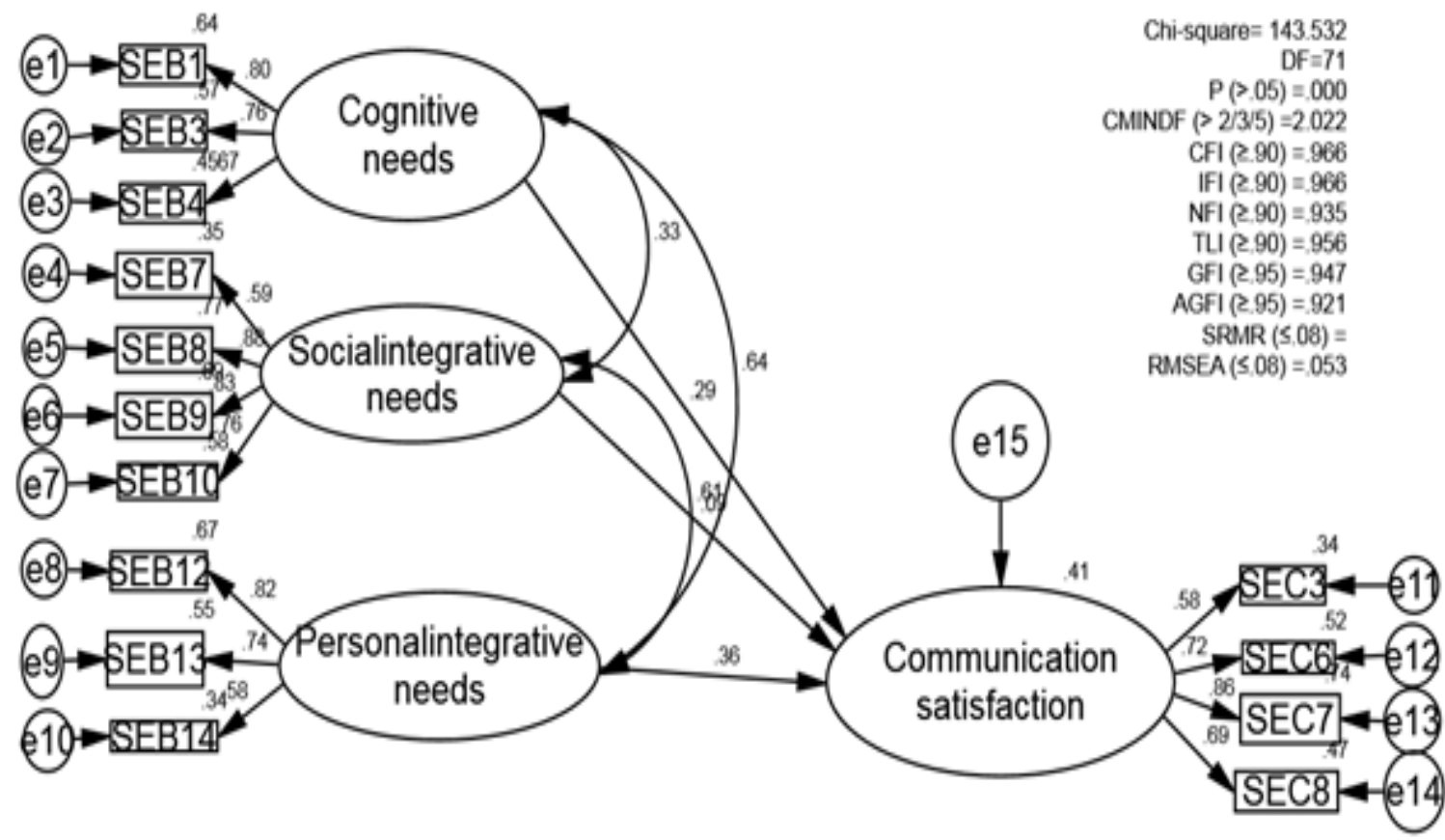

Figure 4: SEM-AMOS Structural Model 


\section{Findings and Interpretations}

This section discussed the South-East Nigerian academic staff demographic profile and research findings.

\section{Profile of south-east Nigerian Academic Staff}

Table 4 presented that the majority of the respondents were men, academic staff. It also showed that about one-third of the respondents' age fell between 31 and 40 years. In terms of the job position, Table 4 stated that more than half of the respondents were in the lecturer position and this comprised the lecturer 1 and 11; assistant lecturers and graduate assistants. Additionally, it demonstrated that more than half of them had doctorate qualifications, while over one- third of them had 1-5 year working experience.

\begin{tabular}{ccc}
\multicolumn{3}{c}{ Table 4: Distribution of Academic Staff Profile $(\mathrm{n}=363)$} \\
\hline Profile & Frequency & Percentage (\%) \\
\hline Gender & 295 & 81.3 \\
Male & 68 & 18.7 \\
Female & & \\
Age & 40 & 11.0 \\
$20-30$ & 122 & 33.6 \\
$31-40$ & 119 & 32.8 \\
$41-50$ & 82 & 22.6 \\
$51>$ & & \\
Job position & 34 & 9.4 \\
Professors & 35 & 9.6 \\
Assoc. Professor & 89 & 24.5 \\
Senior Lecturer & 205 & 56.5 \\
Lecturer & & \\
Highest Educational Qualification & 14 & 3.9 \\
Bachelor Degree & 144 & 39.7 \\
Masters' Degree & 205 & 56.5 \\
Doctorate Degree & & \\
Years of Working Experience & 136 & 37.47 \\
1-5 & 80 & 22.04 \\
6-10 & 64 & 17.63 \\
11-15 & 44 & 12.12 \\
16-20 & 39 & 10.74 \\
21> & &
\end{tabular}

Objective 1: The Respondents' Email Usage Patterns

Table 5 presented the outcomes of the first objective of the respondents' email usage patterns. The table illustrated that all the respondents have at least one email address; in other words, all of them are having an email address. In terms of the numbers of email addresses possessed by the respondents, it showed that more than half of them have two email addresses. Furthermore, the majority of them confirmed they have an official email address. While the majority of them also stated they have a personal email address. In terms of the most preferred email address, the outcomes depicted that almost $70 \%$ of them mostly prefer personal email to an official email address. More than half of them further affirmed they have yahoo and Gmail email addresses. Whilst none of them specifically attested possessing only hot email addresses, however, .08\% of them stated that they have both Gmail and hot email addresses. Regarding the kind of devices, they use to access official email, about half of them specified using smartphones and laptops, while more than half of them declared 
using smartphones and laptops to gain access to personal email addresses. About the duration of using email, the majority of them affirmed having been using email addresses for more than eight years. Consequently, most of the outcomes of this study on email usage patterns were in line with the findings established by (Page, 2015; Mahomed \& Shah, 2015; Alturise, Calder \& Wilkinson, 2014). Moreover, this study's findings illustrated that the majority of the respondents equally possessed both official and personal email addresses for resolving official and personal issues. However, it conspicuously illustrated that most of them prefer using the personal email address to the official one.

Table 5: The Respondents' Email Usage Patterns ( $N=363)$

\begin{tabular}{|c|c|c|}
\hline Items & Frequency & $\%$ \\
\hline \multicolumn{3}{|l|}{ Possessing email } \\
\hline Yes & 363 & 100 \\
\hline No & - & - \\
\hline \multicolumn{3}{|l|}{ Numbers of email address possessed } \\
\hline 1 number of the email address & 53 & 14.6 \\
\hline 2 numbers of the email address & 215 & 59.2 \\
\hline 3 number of the email address & 82 & 22.6 \\
\hline 4 numbers of email address and above & 13 & 3.6 \\
\hline \multicolumn{3}{|l|}{ Possessing an official email address } \\
\hline Yes & 287 & 79.1 \\
\hline No & 76 & 20.9 \\
\hline \multicolumn{3}{|l|}{ Possessing a personal email address } \\
\hline Yes & 351 & 96.7 \\
\hline No & 12 & 3.3 \\
\hline \multicolumn{3}{|l|}{ Most preferred email address } \\
\hline Official email address & 115 & 31.7 \\
\hline Personal email address & 248 & 68.3 \\
\hline \multicolumn{3}{|l|}{ Types of email address possessed } \\
\hline Yahoo email address & 62 & 17.1 \\
\hline Gmail address & 91 & 25.2 \\
\hline Hot Mail address & - & - \\
\hline Both Yahoo and Gmail address & 199 & 55.42 \\
\hline Both Gmail and Hot mail address & 3 & .08 \\
\hline All of the above email address & 8 & 2.2 \\
\hline \multicolumn{3}{|c|}{ Types of devices use in accessing the official email address } \\
\hline Smartphone & 19 & 5.2 \\
\hline Laptop & 43 & 11.8 \\
\hline Desktop & 7 & 1.9 \\
\hline Smartphone and Laptop & 184 & 50.7 \\
\hline Smartphone and Desktop & 1 & .03 \\
\hline Desktop and Laptop & 7 & 1.9 \\
\hline All of the above devices & 50 & 13.8 \\
\hline Not applicable & 52 & 14.3 \\
\hline \multicolumn{3}{|c|}{ Types of devices use in accessing the personal email address } \\
\hline Smartphone & 28 & 7.7 \\
\hline Laptop & 47 & 12.9 \\
\hline Desktop & 4 & 1.1 \\
\hline Smartphone and Laptop & 197 & 54.3 \\
\hline Smartphone and Desktop & 1 & .03 \\
\hline Desktop and Laptop & 3 & .08 \\
\hline All of the above devices & 71 & 19.6 \\
\hline Not applicable & 12 & 3.3 \\
\hline
\end{tabular}




\section{Duration of using email}

$\begin{array}{ccc}\text { Below } 2 \text { years } & 3 & .08 \\ 2-4 \text { years } & 11 & 3.0 \\ 5-7 \text { years } & 70 & 19.3 \\ 8 \text { years and above } & 279 & 76.9\end{array}$

Objective No 2: Outcomes of the Direct Effects Hypotheses of User Motive factors on Email Satisfactory Communication

Table 6 demonstrated the results of the direct effects of the three exogenous variables on email satisfactory communication satisfaction.

Therefore, the first hypothesis in the second research objective hypothesizes that: $\mathrm{H} 1 \mathrm{a}$ : Cognitive needs have direct effects on email satisfactory communication

The structural model analysis outcomes in Table 6, indicated that there are direct effects of cognitive needs on email satisfactory communication $(\beta=.287, p<.05)$. Therefore, hypothesis $\mathrm{H} 1 \mathrm{a}$ is supported. This inferred that every 1 standard deviation increase on cognitive needs, would bring about a $28.7 \%$ standard deviation increase on email satisfactory communication. Additionally, the direct effects of cognitive needs on email satisfactory communication were significant ones. The result intensely supported the finding of Khan (2017) who also established that cognitive needs have a direct effect on the gratifications of virtual communication users. However, the scholar's finding was made through YouTube while the current study ascertained it via an email communication medium.

The 2nd hypothesis in the second research objective states that:

$\mathrm{H} 1 \mathrm{~b}$ : Social integrative needs have a direct effect on email satisfactory communication

According to the analysis outcomes in Table 6, there are no direct effects of social integrative needs on email satisfactory communication $(\beta=.088, p>.05)$. Thus, hypothesis $\mathrm{H} 1 \mathrm{~b}$ is not supported. This implied that social integrative needs have no significant direct effects on email satisfactory communication. Thus, this study's finding sharply contradicted Zhan et al. (2016) and Ang et al. (2015) who previously established significant direct effects of social integrative needs on computer-mediated social media satisfactory interactions. Therefore, variation in the findings might be because the current study's medium of interaction was email, which might not be a socially based medium.

The 3rd hypothesis on the second research objective hypothesizes that:

H1c: Personal integrative needs have direct effects on email satisfactory communication

Based on the analysis result in Table 6, there are direct effects of personal integrative needs on email satisfactory communication $(\beta=.365, p<.05)$. Hence, hypothesis $\mathrm{H} 1 \mathrm{c}$ is supported. It implied that, for every 1 standard deviation increase on personal integrative needs, would surely lead to a $36.5 \%$ standard deviation increase on email satisfactory communication. Consequently, the outcome of the current study supported Zolkepli and Kamarulzaman (2015) who equally hypothesized the direct effects of personal integrative needs on social media satisfactory communication. However, the interaction forum differed 
because the current study made its finding through email mode of communication. Moreover, the direct effect relationship was found to be a significant one.

Table: 6: Analysis of direct effects of the 3 exogenous variables on Communication Satisfaction from the structural (SEM-AMOS) model analysis

\begin{tabular}{cccccc}
\hline & $\mathbf{b}$ & S.E & $\boldsymbol{\beta}$ & CR & P-Level \\
\hline Cognitive Needs & .209 & .062 & .287 & 3.368 & .000 \\
Social Integrative Needs & .082 & .068 & .088 & 1.206 & .228 \\
$\begin{array}{c}\text { Personal Integrative Needs } \\
\mathbf{R}^{2}=.413\end{array}$ & .259 & .077 & .365 & 3.379 & .000 \\
\hline
\end{tabular}

Objective No 3: The User Motive Factor That Contributed Most on Email to a satisfactory Communication

Inferring from the structural model analysis in Table 6, it depicted that the personal integrative needs dimension of the user motive construct contributed most to email satisfactory communication $(\beta=.365, p<.05)$. This indicated it singly yielded a $36.5 \%$ variance on email satisfactory communication. This was followed by cognitive needs in terms of intensifications. Whilst, the social integrative needs contributed the least variance on email satisfactory communication though the contribution was not a significant one. The finding of the current study contradicted Sun et al. (2017) who identified social integrative needs as the strongest factor motivating virtual interaction media users' continuous usage. However, the entire exogenous variables were able to explain $41.3 \%$ of the variance on email satisfactory communication, which was a medium effect size and equally has practical significance according to Nye et al. (2019) effect sizes' rule of thumb.

\section{DISCUSSION OF THE FINDINGS AND STUDY IMPLICATIONS}

This study evaluated the South-East Nigerian academic staff email usage patterns, the user motives factors direct effects on email satisfactory communication and the user motive factor that contributed most to email satisfactory communication among them. In terms of the email usage patterns, we found that their email usage patterns greatly differed from one another. However, the salient email usage pattern demonstrated that nearly the majority of them mostly prefer using the personal email address to the official one. Therefore, it is suggested that important information and urgent issues should be disseminated through personal email addresses if faster responses are anticipated from them. Regarding the findings on the user motive factors' direct effects on email satisfactory communication, we found that only cognitive needs and personal integrative needs had significant direct effects on email satisfactory communication. While social integrative needs did not have significant direct effects on email satisfactory communication. Therefore, these findings implied that using email to achieve some cognitive needs such as using it to disseminate learning materials and retrieve assignments from students, inquiring about unfamiliar information or, seeking other people's views on relevant intellectual issues and other cognitive desires would probably instigate email satisfactory communication. The finding further indicated that using email for accomplishing certain personal research-related needs such as receiving researchrelated updates, enhancing ones' careers and self-esteem through using emails to sign up for academic membership forums such as academia and research Gate; retrieving manuscripts submission updates from journals via email, using email for saving documents and other individual aspirations could lead to email satisfactory communication. Consequently, we 
vehemently recommend that South-East Nigerian academic staff and other email users should explicitly engage email towards achieving their cognitive and personal integrative needs if they aim to attain satisfactory communication via it. However, the findings also showed that social integrative needs did not have significant direct effects on email satisfactory communication, perhaps, it was because it seemed not a socially-oriented medium as the study already established. Moreover, the finding on the user motive factor that contributed most to email satisfactory communication identified that personal integrative needs contributed most to it. Thus, it should be considered most while targeting email satisfactory communication.

The study's findings also have theoretical implications because they proved that the elements of the uses and gratification theory employed and evaluated in the study were able to explain a medium effect size of variance on email satisfactory communication. Consequently, it has helped and expanded the uses and gratification theory. Hence, we commend that prospective scholars on related studies should adopt the model towards exploring other asynchronous virtual media satisfactory communication. However, other antecedents should be integrated into the model since social integrative needs did not have significant direct effects.

\section{BIODATA}

Mrs Chinedu Eugenia Anumudu, is a PhD student in Communication Department, Universiti Putra Malaysia. She studies Communication and Media. Email: munedunwa@gmail.com/chinnyst@gmail.com

Megat Al Imran Yasin (PhD) is a senior lecturer in Communication Department, Universiti Putra Malaysia, and the supervisory committee chairman. Email: megat@upm.edu.my

Akmar Hayati Ahmad Ghazali (PhD) is an associate professor, and a senior lecturer in Communication Department, Universiti Putra Malaysia. She is a supervisory committee Member. Email: akmar@upm.edu.my

Syed Agil Alsagoff (PhD) is a senior lecturer in Communication Department, Universiti Putra Malaysia, and a supervisory committee member. Email: s_agil@upm.edu.my 


\section{REFERENCES}

Agnihotri, R., Dingus, R., Hu, M. Y., \& Krush, M. T. (2016). Social media: Influencing customer satisfaction in B2B sales. Industrial Marketing Management, 53, 172-180.

Alam, A. A. S. (2016). Communication satisfaction: A study on junior executives working in private sector of Bangladesh. Journal of Business and Technology (Dhaka), 69-90.

Al-Menayes, J. J. (2015). Motivations for using social media: An exploratory factor analysis. International Journal of Psychological Studies, 7(1), 43.

Alturise, F., Calder, P. R., \& Wilkinson, B. (2014). E-mail use by the faculty members, students and staff of Saudi Arabian and Gulf states Universities. International Journal of Advanced Computer Science and Applications, 5(9), 123-128.

Ang, C. S., Talib, M. A., Tan, K. A., Tan, J. P., \& Yaacob, S. N. (2015). Understanding computermediated communication attributes and life satisfaction from the perspectives of uses and gratifications and self-determination. Computers in Human Behavior, 49, 20-29.

Anumudu, C. E., Yasin, M. A. I., Ghazali, A. A., \& Alsagoff, S. A. (2020). Redefining immediacy for email satisfactory communication: South-East Nigerian lecturers' perspectives. Jurnal The Messenger, 12(1), 84-96.

Anumudu, C. E., Yasin, M. A. I., Ghazali, A. H. A., \& Alsagoff, S. A. S. (2020). immediacy factors as solutions to email satisfactory communication among South-East Nigerian academic staff: Structural equation modeling and preliminary findings. Jurnal Komunikasi: Malaysian Journal of Communication, 36(2), 212-234.

Baeten, J. J. (2016). The Power of Peer Feedback: Research on the Learning Process within Virtual Action Learning. Eburon Academic Publishers.

Baker, L. R., \& Oswald, D. L. (2010). Shyness and online social networking services. Journal of Social and Personal Relationships, 27(7), 873-889.

Bali Mahomed, A. S. (2015). Examining email usage among non-academic staff in public and private Malaysian universities [Thesis PhD, Victoria University of Melbourne, Australia].

Bankole, O. M. (2013). The use of internet services and resources by scientists at Olabisi Onabanjo University, Ago Iwoye, Nigeria. Program, 47(1), 15-33.

Berger, A. A. (2018). Media and communication research methods: An introduction to qualitative and quantitative approaches. Sage Publications.

Bowden, C., \& Galindo-Gonzalez, S. (2015). Interviewing when you're not face-to-face: The use of email interviews in a phenomenological study. International Journal of Doctoral Studies, 10, 79-93.

Cardon, P. W., \& Marshall, B. (2015). The hype and reality of social media use for work collaboration and team communication. International Journal of Business Communication, 52(3), 273-293.

Chang, I. C., Liu, C. C., \& Chen, K. (2014). The effects of hedonic/utilitarian expectations and social influence on continuance intention to play online games. Internet Research, 24(1), 21-45.

Cecchinato, M. E., Cox, A. L., \& Bird, J. (2015, April). Working 9-5?: Professional differences in email and boundary management practices. Proceedings of the 33rd Annual ACM Conference on Human Factors in Computing Systems (pp. 3989-3998). ACM.

Choi, E., \& Shah, C. (2016). User motivations for asking questions in online Q \& A services. Journal of the Association for Information Science and Technology, 67(5), 1182-1197. 
Coppock, A., \& McClellan, O. A. (2019). Validating the demographic, political, psychological, and experimental results obtained from a new source of online survey respondents. Research \& Politics, 6(1), 2053168018822174.

Creswell, J. W., \& Creswell, J. D. (2017). Research design: Qualitative, quantitative, and mixed methods approaches. Sage publications.

De Schutter, B., \& Malliet, S. (2014). The older player of digital games: A classification based on perceived need satisfaction. Communications, 39(1), 67-87.

Downs, C. W., \& Hazen, M. D. (1977). A factor analytic study of communication satisfaction. The Journal of Business Communication (1973), 14(3), 63-73.

Dunne, Á., Lawlor, M. A., \& Rowley, J. (2010). Young people's use of online social networking sites - A uses and gratifications perspective. Journal of Research in interactive Marketing, 4(1), 46-58.

Email Statistics Report. (n. d.). 2015-2019 - Executive summary. Radicati Group.Com.

Florenthal, B. (2015). Applying uses and gratifications theory to students' Linkedln usage. Young Consumers, 16(1), 17-35.

Funder, D. C., \& Ozer, D. J. (2019). Evaluating effect size in psychological research: Sense and nonsense. Advances in Methods and Practices in Psychological Science, 2(2), 156-168.

Giesbers, B., Rienties, B., Tempelaar, D., \& Gijselaers, W. (2014). A dynamic analysis of the interplay between asynchronous and synchronous communication in online learning: The impact of motivation. Journal of Computer Assisted Learning, 30(1), 30-50.

Gutierrez-Santiuste, E., \& Gallego-Arrufat, M. J. (2015). Internal structure of virtual communications in communities of inquiry in higher education: Phases, evolution and participants' satisfaction. British Journal of Educational Technology, 46(6), 1295-1311.

Ha, Y. W., Kim, J., Libaque-Saenz, C. F., Chang, Y., \& Park, M. C. (2015). Use and gratifications of mobile SNSs: Facebook and KakaoTalk in Korea. Telematics and Informatics, 32(3), 425-438.

Haddouch, R. (2017). The use of email and the relationships between education leaders and followers [Doctoral dissertation, University of Montana].

Hair, J. F., Black, B., Babin, B., Anderson, R. E., \& Tatham, R. L. (2006). Multivariate data analysis (6th ed.). Prentice-Hall, International Inc.

Hair, J., Black, W. C., Babin, B., \& Anderson, R. (2010). Multivariate data analysis (7th ed.). Prentice Hall.

Hanrahan, B. V., Pérez-Quiñones, M. A., \& Martin, D. (2016). Attending to email. Interacting with Computers, 28(3), 253-272.

Holz, R., Amann, J., Mehani, O., Wachs, M., \& Kaafar, M. A. (2015). TLS in the wild: An Internetwide analysis of TLS-based protocols for electronic communication. Cryptography and Security. https://doi.org/10.14722/ndss.2016.23055

Horzum, M. B. (2015). Interaction, structure, social presence, and satisfaction in online learning. Eurasia Journal of Mathematics, Science \& Technology Education, 11(3).

Ifinedo, P. (2016). Applying uses and gratifications theory and social influence processes to understand students' pervasive adoption of social networking sites: Perspectives from the Americas. International Journal of Information Management, 36(2), 192-206.

Iriani, T. (2006). Factors influencing communication satisfaction among e-mail users in selected private organisations in Indonesia [Doctoral dissertation, Universiti Putra Malaysia]. 
Jacobs, M. A., Yu, W., \& Chavez, R. (2016). The effect of internal communication and employee satisfaction on supply chain integration. International Journal of Production Economics, 171, 60-70.

Johnson, P. R., \& Yang, S. (2009). Uses and gratifications of Twitter: An examination of user motives and satisfaction of Twitter use [conference presentation paper]. Communication Technology Division of the annual convention of the Association for Education in Journalism and Mass Communication, Boston, MA.

Kaiser, H. F. (1960). The application of electronic computers to factor analysis. Educational and Psychological Measurement, 20(1), 141-151.

Kang, S., \& Jung, J. (2014). Mobile communication for human needs: A comparison of smartphone use between the US and Korea. Computers in Human Behavior, 35, 376387.

Kang, S. (2014). Factors influencing intention of mobile application use. International Journal of Mobile Communications, 12(4), 360-379.

Katz, E. (1959). Mass communications research and the study of popular culture: An editorial note on a possible future for this journal. Studies in Public Communication, 2, 1-6.

Katz, E., Blumler, J. G., \& Gurevitch, M. (1973). Uses and gratifications research. The Public Opinion Quarterly, 37(4), 509-523.

Katz, E., Blumler, J. G., \& Gurevitch, M. (1974). The uses of mass communication: Current perspectives on gratifications research (Vol. 3 of SAGE Series in Communication Research). SAGE.

Khairani, A. Z., \& Makara, K. A. (2020). Examining the factor structure of the teachers' sense of efficacy scale with Malaysian samples of in-service and pre-service teachers. Pertanika Journal of Social Science and Humanities, 28(1), 309-323.

Khan, M. L. (2017). Social media engagement: What motivates user participation and consumption on YouTube? Computers in Human Behavior, 66, 236-247.

Kitenga, G., Kilika, J. M., \& Muchemi, A. W. (2020). The moderating effect of firm size on the impact of dynamic capabilities on sustainable performance of food manufacturing firms Kenya. Technium Social Sciences Journal, 7, 149-182.

Luo, M. M., \& Remus, W. (2014). Uses and gratifications and acceptance of web-based information services: An integrated model. Computers in Human Behavior, 38, 281295.

Manca, S., \& Ranieri, M. (2016). "Yes for sharing, no for teaching!": Social Media in academic practices. The Internet and Higher Education, 29, 63-74.

Mohamad, M. M., Sulaiman, N. L., Sern, L. C., \& Salleh, K. M. (2015). Measuring the validity and reliability of research instruments. Procedia-Social and Behavioral Sciences, 204, 164-171.

Mohamed, S. F. P., Ku-Mahamud, K. R., Ramli, R., \& Abdullah, K. (2017). Perception and use of e-mail: A case study in Universiti Utara Malaysia. Journal of Telecommunication, Electronic and Computer Engineering (JTEC), 9(2-12), 29-35.

Mukoroi, A. S. (2013). Improving industrial harmony and staff performance in a school organization through effective communication. International Journal of Scientific Research in Education, 6(3), 263-270.

Nye, C. D., Bradburn, J., Olenick, J., Bialko, C., \& Drasgow, F. (2019). How big are my effects? Examining the magnitude of effect sizes in studies of measurement equivalence. Organizational Research Methods, 22(3), 678-709. 
Oh, H. J., Ozkaya, E., \& Larose, R. (2014). How does online social networking enhance life satisfaction? The relationships among online supportive interaction, affect, perceived social support, sense of community, and life satisfaction. Computers in Human Behavior, 30, 69-78.

Ogara, S. O., Koh, C. E., \& Prybutok, V. R. (2014). Investigating factors affecting social presence and user satisfaction with mobile instant messaging. Computers in Human Behavior, 36, 453-459.

Omeluzor, S. U., Akibu, A. A., \& Akinwoye, O. A. (2016). Students' perception, use and challenges of electronic information resources in Federal University of petroleum resources Effurun Library in Nigeria. Library Philosophy and Practice (E-Journal), 1428.

Olatokun, W. M. (2017). Availability, accessibility and use of ICTs by Nigerian women academics. Malaysian Journal of Library \& Information Science, 12(2), 13-33.

Page, D. (2015). Teachers' personal web use at work. Behaviour \& Information Technology, 34(5), 443-453.

Park, N., Kee, K. F., \& Valenzuela, S. (2009). Being immersed in social networking environment: Facebook groups, uses and gratifications, and social outcomes. CyberPsychology \& Behavior, 12(6), 729-733.

Pendry, L. F., \& Salvatore, J. (2015). Individual and social benefits of online discussion forums. Computers in Human Behavior, 50, 211-220.

Phua, J., Jin, S. V., \& Kim, J. J. (2017). Uses and gratifications of social networking sites for bridging and bonding social capital: A comparison of Facebook, Twitter, Instagram, and Snapchat. Computers in Human Behavior, 72, 115-122.

Pritchett, K. M., Naile, T. L., Murphrey, T. P., \& Reeves, L. F. (2014). Participant satisfaction related to social presence in agricultural conversations using Twitter: Implications for agricultural communications. Journal of Applied Communications, 98(3). https://doi.org/10.4148/1051-0834.1084

Sacco, D. F., \& Ismail, M. M. (2014). Social belongingness satisfaction as a function of interaction medium: Face-to-face interactions facilitate greater social belonging and interaction enjoyment compared to instant messaging. Computers in Human Behavior, 36, 359-364.

Sheldon, P., \& Bryant, K. (2016). Instagram: Motives for its use and relationship to narcissism and contextual age. Computers in human Behavior, 58, 89-97.

Sumter, S. R., Vandenbosch, L., \& Ligtenberg, L. (2017). Love me Tinder: Untangling emerging adults' motivations for using the dating application Tinder. Telematics and Informatics, 34(1), 67-78.

Sun, J., Sheng, D., Gu, D., Du, J. T., \& Min, C. (2017). Understanding link sharing tools continuance behavior in social media. Online Information Review, 41(1), 119-133.

Swacha, J. (2015). Management by email reinterpreted with a process-based approach. Proceedings of the MakeLearn and TIIM Joint International Conference 2015 (pp. 1343-1350). ToKnowPress.

Tiwari, S. K. (2016). A study on impact of ICT on library and information services. International Journal of Recent Advances in Engineering \& Technology, 4(1), 26-31.

Turnage, A. K., \& Goodboy, A. K. (2016). E-mail and face-to-face organizational dissent as a function of leader-member exchange status. International Journal of Business Communication, 53(3), 271-285.

Whiting, A., \& Williams, D. (2013). Why people use social media: A uses and gratifications approach. Qualitative Market Research: An International Journal, 16(4), 362-369. 
Zhan, L., Sun, Y., Wang, N., \& Zhang, X. (2016). Understanding the influence of social media on people's life satisfaction through two competing explanatory mechanisms. Aslib Journal of Information Management, 68(3), 347-361.

Zolkepli, I. A., \& Kamarulzaman, Y. (2015). Social media adoption: The role of media needs and innovation characteristics. Computers in Human Behavior, 43, 189-209. 